\title{
Responses of epibenthic and nektonic macroinvertebrate communities to a gradient of fish size in ponds
}

\author{
Marek NIEOCZYM ${ }^{1 *}$ Janusz KLOSKOWSKI ${ }^{2}$ \\ ${ }^{1}$ Department of Zoology, Animal Ecology and Hunting, University of Life Sciences, Akademicka 13, 20-033 Lublin, Poland; \\ ${ }^{2}$ Department of Nature Conservation, Institute of Biology, Maria Curie-Skłodowska University, Akademicka 19, 20-033 Lublin, Poland \\ *Corresponding author: mnieoczy@wp.pl
}

\begin{abstract}
Size relationships between fish and organisms from adjacent trophic levels are crucial for predicting the structure and dynamics of aquatic ecosystems. We compared macroinvertebrate communities along a fish-size gradient created by separate stocking of three age cohorts of common carp Cyprinus carpio in semi-natural ponds. The specific size range of fish (small, medium and large) corresponding to fish age in ponds was the factor most strongly associated with macroinvertebrate composition. The other significant habitat variables were dissolved oxygen concentration in the water and submerged vegetation abundance in the open-water zone. Among the most numerous taxa in the ponds, relative abundances of Hirudinea, Gastropoda, Odonata and Coleoptera were larger in the presence of smallsized than of larger-sized carp. However, fish size effect was not linear, in that macroinvertebrate assemblages were less similar between ponds containing medium- vs large-sized fish than between ponds with small-vs large-sized fish. The dissimilarity patterns were mainly determined by disparities in abundance of Corixidae, which unlike other taxa common in the ponds occurred in the greatest numbers in the presence of large-sized carp. Macroinvertebrate diversity was greatest in ponds with small-sized fish and was positively related to emergent macrophyte cover. Enhancement of emergent vegetation is recommended as the most effective management strategy to buffer adverse impacts of fish on macroinvertebrates. If fish are present in the system, assessment of the size structure of fish populations can be advantageous in unravelling the essential processes driving the variation in pond communities.
\end{abstract}

Key words: Body size, community structure, macroinvertebrates, ponds, size distribution, trophic interactions.

Received: March 2014. Accepted: July 2014.

\section{INTRODUCTION}

Fish often play a key role in shaping aquatic communities. Besides pronounced trophic effects, some fish, especially benthivores, may alter entire food webs by modifying environmental conditions, e.g., through elevation of water turbidity and nutrient loads (Richardson et al., 1990; Bremigan et al., 1997; Scheffer, 1989). A number of studies have explored the influence of fish on aquatic macroinvertebrates, using comparisons of assemblages or densities of selected taxa under conditions of the presence or absence of fish, or relating them to fish densities. It has been widely documented that macroinvertebrate abundance is higher in fish absence (Morin, 1984; Bendell and McNicol, 1995; Fairchild et al., 2000; Zimmer et al., 2000; but see Batzer et al., 2000; Johansson and Brodin, 2003) and typically inversely related to fish densities (Svensson et al., 1999; Dorn, 2008; Martínez-Sanz et al., 2012; but see Paukert and Willis, 2003; Michaletz et al., 2005). However, most of the research on fish-macroinvertebrate interactions has not taken into account the effects of fish body size. Fish populations often show distinct size structure because of interactions between and within species or periods of size-selective survival and poor recruitment typical of wa- ters impacted by environmental perturbations (Penttinen and Holopainen, 1992; Lake, 2003; Dorn, 2008; Bajer and Sorensen, 2010). Fish body growth through ontogeny is accompanied by shifts to new niches, as the feeding mode and food-size limitations change (Mark et al., 1987; Penttinen and Holopainen, 1992; Gustafsson et al., 2010). Consequently, the size structure of fish populations, combined with the numerical dominance of individual species, can be crucial in determining the character and strength of fish-invertebrate interactions. Given the wide range of trophic positions occupied by aquatic macroinvertebrates, alterations in their community dynamics may in turn be transmitted to multiple trophic levels (Bendell and McNicol, 1995; Parkos et al., 2003).

Here, we investigated responses of macroinvertebrate communities to fish of different size in ponds stocked with common carp Cyprinus carpio Linnaeus, 1758. Carp, a popular food and sport fish globally introduced into natural and artificial freshwater habitats, has been linked to dramatic declines in native biodiversity (Tapia and Zambrano, 2003; Matsuzaki et al., 2009; Bajer and Sorensen, 2010). The detrimental influence is generally thought to be mediated by increased turbidity levels due to excretion and bioturbation resulting from specific feeding behav- 
iour, i.e. suction of benthic material and ejection of unused particles back into the water column (Sibbing, 1988), but carp's trophic impact can be considerable as well (Britton et al., 2007; Kloskowski, 2011c). Carp can attain a substantial body size and undergo extensive ontogenetic shifts in resource use (Crivelli, 1981; Garcia-Berthou, 2001), feeding chiefly on zooplankton at the early developmental stages, but later exploiting a wide spectrum of food with an increasing share of benthic and epibenthic macroinvertebrates (Adámek et al., 2003; Britton et al., 2007; Kloskowski, 2011b). As carp increase in size they are capable both of taking larger food items and of foraging deeper in the sediment (Sibbing, 1988; Hasan and MacIntosh, 1992; García-Berthou, 2001), and thus exert broader environmental influence (Driver et al., 2005; Kloskowski, 2011b). We investigated differences in assemblage composition and abundance of aquatic macroinvertebrates along a fish-size gradient in semi-natural ponds, where age-cohorts of carp differing clearly in body-size ranges were separately stocked. Our 'natural experiment' approach mimicked whole-system experiment design; while retaining the complexity of pond com- munities, it aimed to separate the effects of fish of different size ranges. We predicted that the adverse effect of fish would increase along the size gradient. We also examined what other pond habitat features contributed to variation in macroinvertebrate diversity and taxonomic composition.

\section{METHODS}

The research was carried out on semi-extensively managed ponds used for fish culture in the Lublin region (51 $\left.1^{\circ} 17-33^{\prime} \mathrm{N}, 22^{\circ} 15-26^{\prime} \mathrm{E}\right)$, south-eastern Poland (Fig. 1), in 2005-2007, as part of a larger study on the role of size structure of fish populations in pond ecosystems (Kloskowski, 2010; Nieoczym and Kloskowski, 2014). Since carp and aquatic macroinvertebrates strongly interact with diverse taxa, including amphibians and waterbirds, the research covered the period from late April to mid-July, which is critical for the overall biodiversity of pond habitats. A fish-size gradient was created by stocking three carp year cohorts, each with a distinct size range, in separate ponds. Data on total weights and numbers of fish stocked

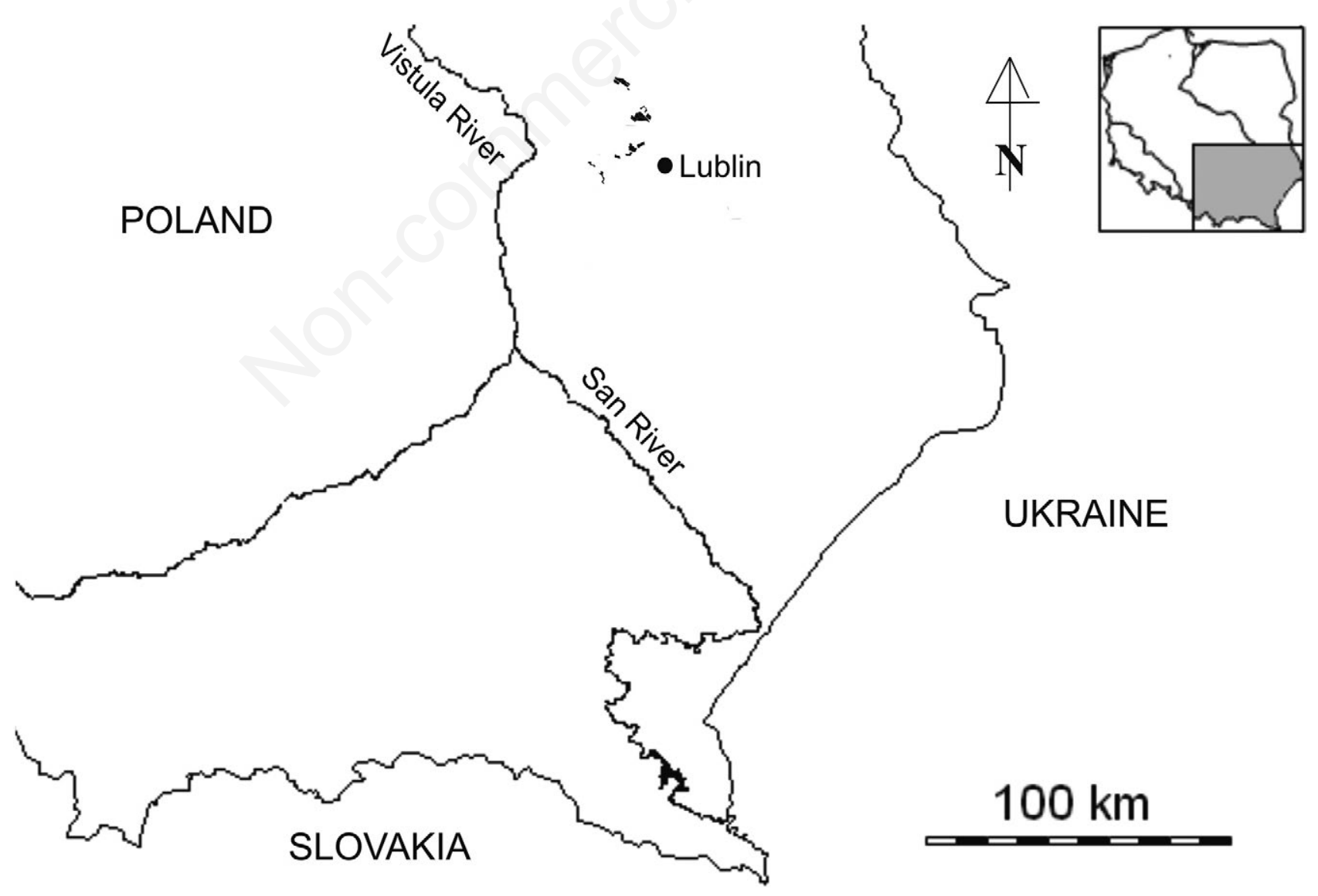

Fig. 1. Location of study ponds in south-eastern Poland. Inset shows location of map within Poland. 
in each pond were provided by the local fisheries. Fish lengths were back-calculated using length-weight regressions established from samples collected in the study area. The ponds were stocked with either young-of-the-year (YOY, small-sized), one-year-old (medium-sized) or twoyear-old (large-sized) carp. As the cohort age corresponded to a specific size range, fish age is here considered equivalent to body size. Fish size ranges (total length) were 3-4 $\mathrm{mm}$ (1.5-3.0 mg), 110-160 mm (ca. 30-60 g) and 190-240 $\mathrm{mm}$ (ca. 140-300 g). As carp fry are sensitive to cold spells, YOY carp were not introduced into the ponds until ca. mid-May; older fish were stocked in late March and in April. Since individual weight at stocking was very small, standing biomass of YOY carp was practically negligible during the early study period, but by mid-July it had attained ca. $50 \mathrm{~kg} / \mathrm{ha}$ (individual weight 6-20 g, equivalent to ca. 6-9 $\mathrm{cm}$ total length). Medium-sized fish were stocked at biomass densities of $98-390 \mathrm{~kg} / \mathrm{ha}$ and largesized carp at biomass densities of 149-308 kg/ha. Fish were supplied with milled cereal grains (YOY carp from July and older carp from May).

Altogether 35 ponds, clustered in four groups up to ca. $30 \mathrm{~km}$ from each other, were sampled, 12 ponds per year in 2005 and 2007 and 11 ponds in 2006. The ponds, embedded in a mainly agricultural landscape, were of similar depth (mean values varying from 0.7 to $1.3 \mathrm{~m}$ over the study period), but differed in surface area (1-13 ha and one pond of $23 \mathrm{ha}$ ). Selected limnological characteristics of the study ponds are presented in Supplementary Tab. 1. The ponds were similar in their main abiotic characteristics; however, ponds holding larger fish tended to be larger in surface area than ponds with smallsized fish, while the latter were characterised by higher water transparency (Tab. 1). Turbidity levels were generally moderate during the study period, only exceptionally exceeding $20 \mathrm{NTU}$, a threshold value over which macrophyte growth can be seriously impaired (Lougheed et al., 1998), but increased in all types of ponds as the season progressed (Nieoczym and Kloskowski 2014).
For more details on the study system see Kloskowski (2010) and Nieoczym and Kloskowski (2014).

\section{Macroinvertebrate sampling}

Submerged activity traps, made of 1 -L plastic cylinders with funnels $100 \mathrm{~mm}$ at the large end and $23 \mathrm{~mm}$ at the narrow end (Fig. 2), were used to collect epibenthic and nektonic macroinvertebrates (Hyvönen and Nummi, 2000). In each pond ten traps were deployed for $24 \mathrm{~h}$ at half-month intervals from the second half of April through mid-July (six sampling sessions per season). All ponds were sampled on the same dates within a given sampling event. The traps were placed horizontally on the bottom (Fig. 2) at least $10 \mathrm{~m}$ apart, at the interface between open water and emergent vegetation along the pond margins, in order to collect both species inhabiting open water and those associated with emergent macrophyte stands. The contents of the traps were sieved. Macroinvertebrates (i.e., invertebrates other than microcrustacean zooplankton, retained by a $1-\mathrm{mm}$ sieve) were preserved in a $4 \%$ formalin solution. In the laboratory they were counted and identified - Hirudinea to at least subclass, Gastropoda to family, and Arthropoda to at least order level. Trap catches were expressed as the number of individuals per 10 traps. We acknowledge that the use of traps alone may have limited our ability to fully characterise the macroinvertebrate communities, as they are most suitable for sampling nektonic invertebrates; nonetheless they are efficient in collecting a wide range of species and are easily standardised between field workers (Murkin et al., 1983; Hyvönen and Nummi, 2000), so the comparisons of relative abundances of individual taxa between ponds with different-sized fish should not be biased.

\section{Environmental variables}

Chemical and physical water quality parameters were examined on the sampling dates in the second half of June and in July and means of the measurements were used in

Tab. 1. Summary statistics for basic habitat attributes measured at ponds with small-, medium- and large-sized fish. Data are means \pm standard deviation, with range in parentheses. The variables did not differ among ponds with different-sized fish ( $\mathrm{P}>0.2)$, with the exception of pond size and Secchi transparency (mixed-model ANOVA with the identity of the sampling year and of the pond cluster entered as random factors, $\mathrm{F}_{2,28}=8.76, \mathrm{P}=0.001$ and $\mathrm{F}_{2,28}=4.18, \mathrm{P}=0.026$, respectively).

\begin{tabular}{lccc}
\hline Parameter/Ponds & Small carp & Medium carp & Large carp \\
& $n=12$ & $n=13$ & $22.6 \pm 16.2(5-57)$ \\
Emergent vegetation $(\%)$ & $34.4 \pm 12.2(17-56)$ & $33.8 \pm 18.3(8-68)$ & $9.4 \pm 6.0(2-23)$ \\
Surface (ha) & $2.4 \pm 1.1(1-5)$ & $4.4 \pm 2.4(2-8)$ & $8.5 \pm 0.7(7.2-9.4)$ \\
$\mathrm{pH}$ & $8.1 \pm 0.5(7.6-9.4)$ & $7.9 \pm 0.6(6.8-9.1)$ & $383.2 \pm 66.8(272-462)$ \\
Conductivity $\left(\mu \mathrm{S} \mathrm{cm}^{-1}\right)$ & $407.2 \pm 89.5(273-590)$ & $6.1 \pm 2.2(1.3-9.6)$ & $6.9 \pm 1.2(5.8-9.1)$ \\
Dissolved oxygen $\left(\mathrm{mg} \mathrm{dm}^{-3}\right)$ & $5.1 \pm 1.5(2.3-8.1)$ & $52.3 \pm 25.4(20-97)$ & $58.6 \pm 28.5(33-125)$ \\
Secchi disc $(\mathrm{cm})$ & $90.8 \pm 25.9(47-150)$ &
\end{tabular}


the analyses (Tab. 1). A 12-cm Secchi disc was used to estimate water transparency. Water conductivity, $\mathrm{pH}$ and dissolved oxygen concentrations were measured using portable meters. Submerged vegetation was collected in the open-water zone using a Bernatowicz sampler, a mechanical grab fitted with macrophyte-cutting jaws (two toothed metal frames sampling an area of $0.16 \mathrm{~m}^{2}$ ), between 30 June and 2 July (Nieoczym and Kloskowski 2014). Since we could not exclude gradients of submerged vegetation, sampling progressed along two perpendicular 30-45 m transects per pond. Eight samples were collected in total and the above-ground biomass was calculated in $\mathrm{g} / \mathrm{m}^{2}$. The samples were washed, dried until a constant weight was reached, and weighed. The most common macrophyte species are listed in Supplementary Tab. 1. Other pond variables included in the analyses were pond surface area (ha), percent cover of emergent aquatic vegetation (determined by digitising aerial photographs), pond duration and fish age in the pond as a proxy for fish size. Pond duration was expressed as one of two classes, permanent ponds storing water from at least the preceding winter and temporary ponds filled with water only in late spring, $\mathrm{n}=14$ and 21 ponds, respectively.

\section{Data analysis}

As the ponds studied were spatially clustered and sampling was conducted over three years, to factor out potential spatial autocorrelation and year effects we included pond cluster and year identifiers as either nominal covariables or random terms in the analyses. Owing to the much

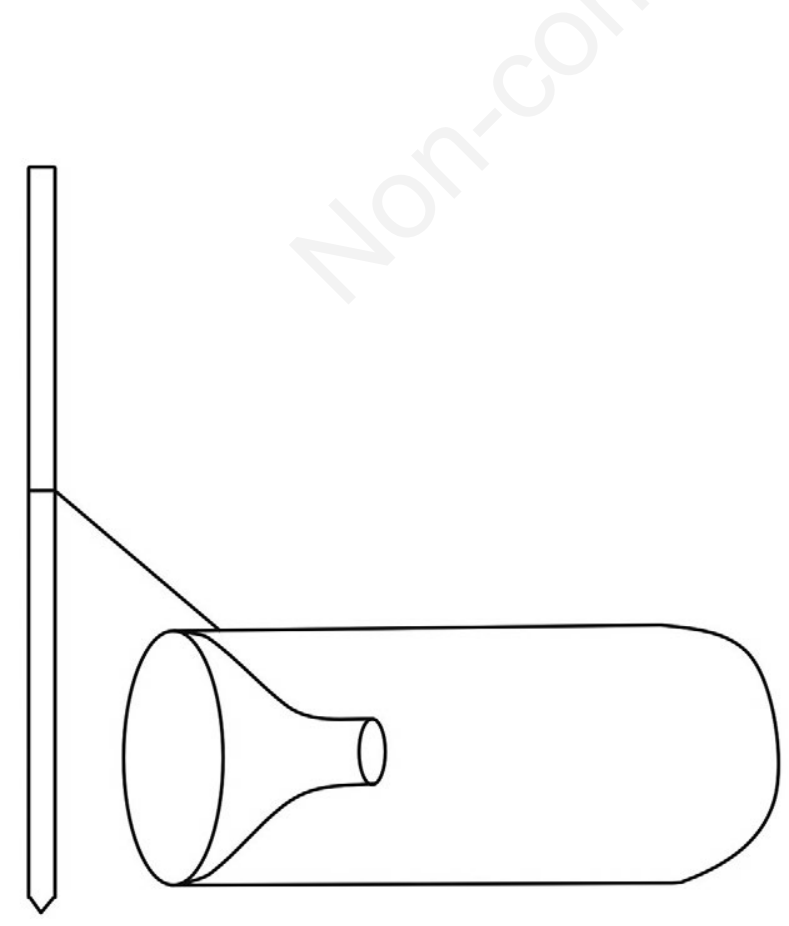

Fig. 2. Activity trap design, lateral view. smaller individual biomass of YOY carp, their stocks had naturally lower standing biomass than those of older and larger fish, despite numerical densities that were higher by two orders of magnitude. Consequently, total fish biomass density was not independent of individual size in our study system. In the analyses, either the two effects were entered into separate analyses (i.e., in the absence of the other variable) or biomass effect was omitted (when, based on preliminary analyses, individual fish size appeared to be a stronger predictor of macroinvertebrate community composition or diversity). Fish age (as a proxy for individual size) was treated as a categorical variable, with the exception of Canonical Correspondence Analysis (see below), where we were interested in obtaining a graphical vector of fish-size effect.

Canonical Correspondence Analysis (CCA), a multivariate, direct-gradient technique that simultaneously ordinates taxa, samples and environmental variables in low-dimensional space (ter Braak, 1986), was applied to assess how well the environmental variables accounted for variation in the macroinvertebrate assemblage patterns. The ordination axes extracted by this technique are uncorrelated and constrained to be linear combinations of the environmental variables (ter Braak, 1986). Taxa scores were divided by standard deviation. To account for phenological differences, e.g., emergence patterns between taxa, macroinvertebrate abundances per pond were expressed as maximum numbers of individuals captured in any one sampling event. In order to lessen the disproportionate effects of rare species, taxa and their developmental stages (depending on the type of metamorphosis) whose absolute frequency of occurrence in ponds was $<10 \%$ over all sampling events and pond types throughout the three seasons were either combined or removed. CCA analyses were limited to the ten most commonly encountered groups: Gastropoda, Hirudinea, Ephemeroptera (naiads), Anisoptera (nymphs), Zygoptera (nymphs), Corixidae (nymphs and imagines), Ilyocoris cimicoides (Linnaeus, 1758) (nymphs and imagines), Notonectidae (nymphs and imagines), Coleoptera (larvae and imagines), which were assigned to two guilds: predaceous (mainly Dytiscidae) and herbivorous Coleoptera (Haliplidae, Chrysomelidae and Hydrophilidae; of the Chrysomelidae and Hydrophilidae only adults were collected). Guild assignment generally followed Wetzel (1983); a few Haliplidae adults trapped were allocated to herbivorous Coleoptera even though they might have been omnivorous, because of the small body size of these individuals, which limited potential predation to very small organisms. We conducted a partial CCA with pond clusters and the year of sampling specified as dummy covariables. Of the environmental variables, pond duration was entered as a nominal term. To preclude multicollinearity issues, we first performed partial CCA for paired explanatory variables which were intercorrelated at $\mathrm{P}<0.01$ and eliminated 
the variable with the lower marginal effect. In this way, collective fish biomass and pond surface area were deleted from the ordination analyses, as they were correlated with fish size but with lesser explanatory effect. The complexity of the model was reduced by means of a forward selection procedure; the significance of the relationship of each environmental variable to the taxonomic variables was determined by the magnitude of the additional variation the variable explained (conditional effects) with $\alpha=0.1$ for acceptance into the final model. The Monte Carlo procedure, based on 999 random permutations, was used to test the significance of individual variables, as well as that of the first ordination axis and of the overall ordination pattern. Intra-set correlations (between the environmental variables and the ordination axes derived from the environmental data) were examined to assess the importance of individual environmental variables (ter Braak, 1986).

Analysis of similarities (ANOSIM, Clarke and Green, 1988), based on Bray-Curtis distance, was used to test for differences in macroinvertebrate assemblages among ponds stocked with different-sized fish. ANOSIM is a hypothesis-testing permutation procedure that generates a probability value and a test statistic $\mathrm{R}$ reflecting the degree of similarity between groups. For pairwise comparisons between pond types, the sequential Bonferroni correction was applied (999 permutations for each comparison). Subsequently, we conducted SIMPER (similarity percentages) analysis to quantify the contribution of the different taxa to the dissimilarity. The taxonomic diversity of pond macroinvertebrates in relation to the environmental variables was quantified using the Shannon-Wiener index ( $\left.\mathrm{H}^{\prime}\right)$. The index accounts for the total number of taxa as well as for their evenness across the sampling sites (Margalef, 1958). We used the same taxonomic levels as in the CCA, but Gastropoda were analysed at family level, and less frequently occurring taxa (omitted from the CCA) were also included: Isopoda [Asellus aquaticus (Linnaeus, 1758)], Araneae [Argyroneta aquatica (Clerck, 1758)], Hemiptera [Nepa cinerea (Linnaeus, 1758)], Megaloptera (Sialis sp.) and Trichoptera. Generalised linear mixed models (GLMMs) using a stepwise backward procedure were performed; factors treated in the CCA as covariables were fitted as random terms. In order to examine potential differences in relative abundances of the most abundant macroinvertebrates in the presence of fish of different size, we applied repeated measures (RM-) ANOVA with the independent factor of carp age and with time as the repeated measure. For ANOVA analyses all Odonata and Coleoptera were grouped into orders. Significance was assessed using a sequential Holm correction (Holm, 1979) with $\alpha=0.05$. Homogeneities of the variances were tested by Box's test. When the F-test was significant for fish age, we performed post-hoc least significant difference (LSD) tests.

Data were $\log (\mathrm{x}+1)$ or $\arcsin$ transformed to meet the requirements of equal normality and variance, with the exception of species data in the CCA, as this method does not depend on parametric distributional assumptions (Palmer, 1993). The CCAs were run with the program CANOCO 4.5 (ter Braak and Šmilauer, 2002), and ANOSIM and SIMPER were calculated using PAST (Hammer et al., 2001) ver. 2.17. Other statistical analyses were performed using the GenStat 15 package (VSN International Ltd).

\section{RESULTS}

Overall, insects were the most abundant macroinvertebrates in the traps: Heteroptera (49.1-67.1\% per sampling session, of these 58.1-96.7\% Corixidae, dominated by Sigara falleni Fieber, 1848), Coleoptera (2.5-23.8\%, of these $23.9-99.3 \%$ Dytiscidae) and Odonata (0-10.3\%). The other common taxa were Hirudinea (2.7-19.6\%), dominated by Erpobdellidae and Glossiphonidae, and Gastropoda (1.4-7.5\%), mainly Lymnaeidae and Planorbidae.

The forward selection procedure of the CCA reduced the data set to seven environmental variables (Fig. 3). Based on the selection, fish age (size) in the ponds $\left(\lambda_{\mathrm{a}}=0.28, \mathrm{~F}=8.01, \mathrm{P}<0.001\right)$, dissolved oxygen concentration $\left(\lambda_{\mathrm{a}}=0.09, \mathrm{~F}=2.55, \mathrm{P}=0.034\right)$ and submerged vegetation abundance $\left(\lambda_{\mathrm{a}}=0.08, \mathrm{~F}=2.65, \mathrm{P}=0.022\right)$ were the habitat factors best explaining distance among macroinvertebrate taxa centroids. The other environmental variables included in the model were emergent vegetation, water conductivity, pond duration and $\mathrm{pH}$ (all $\lambda_{\mathrm{a}}>0.04$, $\mathrm{F} \geq 1.43, \mathrm{P}<0.09$ ). The CCA yielded four canonical axes (the main results for the first three canonical axes are given in Tab. 2), accounting for a cumulative $37.8 \%$ of the variance in the taxa data; the first and the second CCA axis explained $18.6 \%$ and $11.3 \%$ of the variance, respectively. The eigenvalues were affected by the variation among study sites (pond clusters); inclusion of the pondcluster identifiers not as a covariable but as a nominal variable increased the percentage of total variance explained to $58.6 \%$. Axis 1 of the CCA was a gradient of increasing fish age and dissolved oxygen concentration, and decreasing cover of emergent vegetation (Pearson $\mathrm{r}=-0.917,-0.737$ and 0.449 , respectively); axis 2 was largely defined by pond duration, contrasted between temporary and permanent ponds, and by submerged macrophytes abundance $(\mathrm{r}=0.538$ and 0.426 , respectively) (Fig. 3), while axis 3 was most strongly related to submerged and emergent vegetation $(r=0.528$ and 0.405 , respectively) (all $\mathrm{P}<0.05$ ). The Monte Carlo permutation test showed the model to be significantly better than a randomly generated one $(\mathrm{F}=7.52, \mathrm{P}=0.006$ for the first canonical axis and $\mathrm{F}=3.36, \mathrm{P}=0.001$ for the total model; trace value $=0.657$ ). Fish age (size) was negatively associated with relative abundances of most macroinvertebrate taxa (Fig. 3). Along the same gradient of the first CCA axis, 
dissolved oxygen concentrations were either unrelated or negatively associated with macroinvertebrates (the only significant correlation found was with predatory Coleoptera, $\mathrm{r}=0.382, \mathrm{P}=0.026$ ). Ephemeroptera and Corixidae were the only taxa positively correlated with fish size ( $\mathrm{r}=0.335, \mathrm{P}=0.049$ and $\mathrm{r}=0.299, \mathrm{P}=0.082$, respectively); moreover, Corixidae was the single group showing a positive (although again only marginally significant) association with permanent ponds ( $\mathrm{r}=0.304$, $\mathrm{P}=0.076$ ).

The results of ANOSIM indicated that macroinvertebrate communities varied among ponds differing with fish size (global $\mathrm{R}=0.238, \mathrm{P}<0.001$ ). Pairwise tests revealed sig- nificant differences between ponds with medium-sized carp and the other pond types ( $\mathrm{P}<0.001$ in both cases). The dissimilarity between communities in ponds with small- $v s$ large-sized carp only approached significance $(\mathrm{P}=0.108$ after Bonferroni correction). Corixidae, Hirudinea and predaceous Coleoptera contributed most to the observed dissimilarity between the groups (SIMPER analysis, 43.9, 13.8 and $11.7 \%$, respectively). The GLMMs showed that macroinvertebrate diversity was positively related to fish size $\left(\mathrm{F}_{2,31}=7.50, \mathrm{P}=0.002\right)$ and emergent vegetation cover $\left(\mathrm{F}_{1,31}=10.37, \mathrm{P}=0.003\right)$. The mean diversity estimates were significantly greater for ponds containing small fish than ponds stocked with medium- or large-sized fish (post-hoc

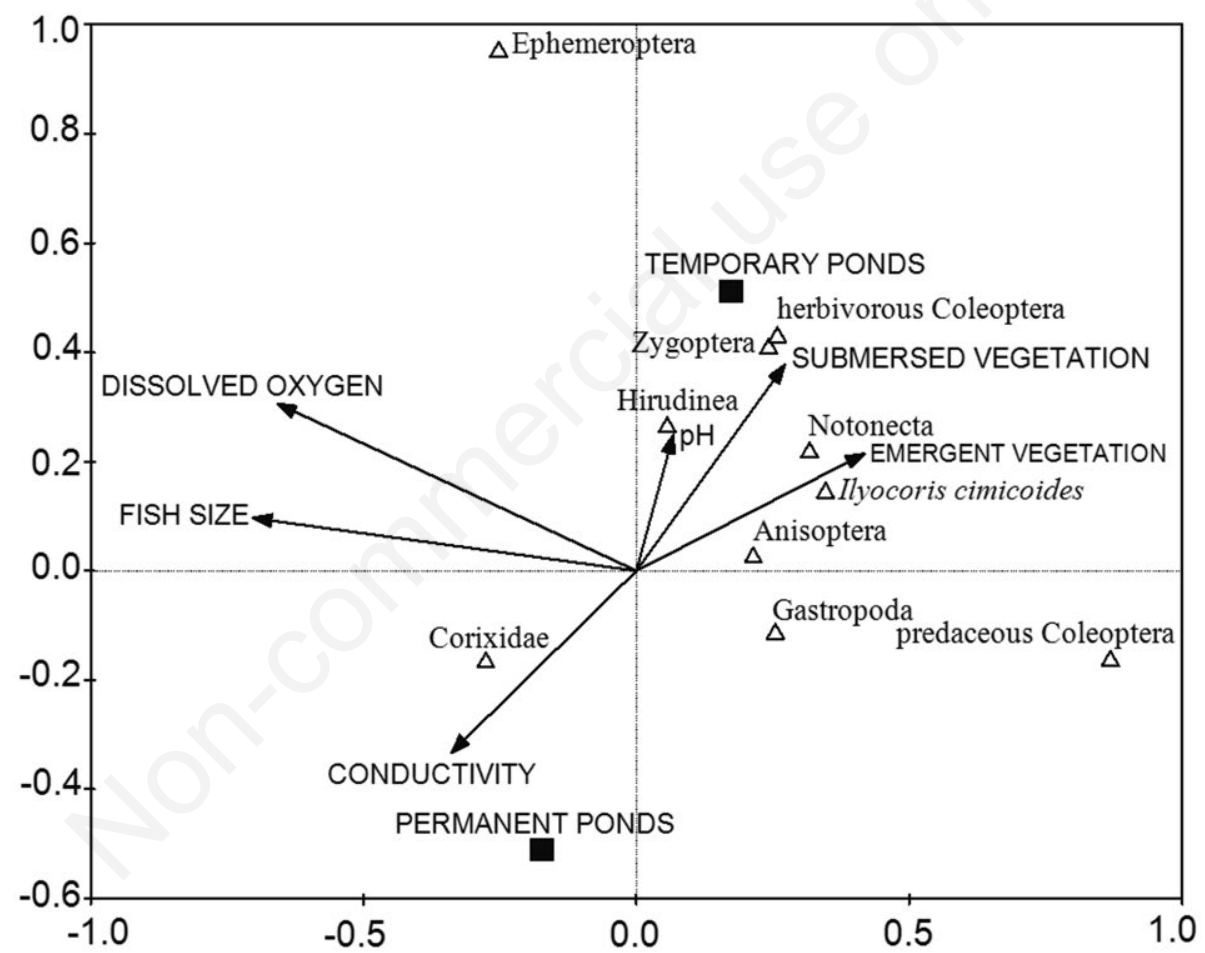

Fig. 3. Biplots of the first and second CCA axes based on relative abundances of pond macroinvertebrates. Environmental variables which passed the forward selection (P set at 0.1 ) are depicted by arrows (square centroids for pond duration as the only qualitative variable).

Tab. 2. Summary of canonical correspondence analysis results, relating relative abundances of macroinvertebrates to environmental variables. Values for three canonical axes are shown. The inertia (a measure of the total amount of variance in the species composition) in the species data set was 1.776 .

\begin{tabular}{lccc}
\hline Variables & & CCA axes & Axis 3 \\
\hline Eigenvalues & Axis 1 & Axis 2 & 0.096 \\
Species-environment correlations & 0.323 & 0.196 & 0.676 \\
Cumulative \% variance of species data & 0.874 & 0.870 & 48.4 \\
Cumulative \% variance of species-environment relation & 25.5 & 40.9 & 93.7 \\
\hline
\end{tabular}


analysis by LSD tests; Shannon-Wiener H', 1.717 vs 1.012 and 0.791 , respectively).

RM ANOVA indicated that abundance of dominant macroinvertebrate taxa depended on carp size (Fig. 4); for Hirudinea the effect was only marginally significant after Holm's correction (Tab. 3). LSD follow-up comparisons showed that mean relative abundances were overall higher in ponds containing small-sized carp than in ponds with larger-size fish, while ponds stocked with the two largersize classes did not differ significantly. Large-bodied (body length $>1 \mathrm{~cm}$ ) Coleoptera occurred only exceptionally in ponds with larger carp (altogether five individuals were recorded on three occasions) and their relative abundances were 29-fold lower relative to ponds with YOY carp. The only exception among the major groups was Corixidae, which were more abundant in ponds with large-sized fish than in ponds with medium-sized fish; their relative abundances in ponds with small-sized fish were intermediate, not significantly different from values for small and medium carp (Fig. 4d). We did not observe any significant relationship between fish standing biomass and macroinvertebrate relative abundances. Time effect and interaction fish size*time was significant for all taxa tested except for Coleoptera (Tab. 3). Note that this was not an artefact of combining developmental stages or various families, because models including only adult Coleoptera or only adult Dytiscidae produced results of similar significance (time, both $\mathrm{F}_{5,160} \leq 1.67, \mathrm{P} \geq 0.182$; fish size*time, both $\mathrm{F}_{10,160} \leq 1.00, \mathrm{P} \geq 0.425$ ). With the exception of Corixidae, which showed a significant increase in numbers in ponds with large-sized fish in the second half of June and in July (Fig. 4d), macroinvertebrate relative abundances in the presence of larger carp were consistently low throughout the study period and did not reveal any seasonal variation. In ponds with small-sized fish, traps yielded increasing Gastropoda numbers from the second half of May, while Hirudinea and Odonata showed an abundance peak in the second half of June (LSD tests).

\section{DISCUSSION}

Fish size proved to be the best correlating parameter for predictions of macroinvertebrate distribution among

Tab. 3. Repeated measures ANOVA (with time as the repeated measure) for the effects of fish individual size and standing biomass on the relative abundances of numerically dominant macroinvertebrates. Separate models were run for these effects because of multicollinearity issues. For the models with biomass density as the treatment factor only main treatment effects are reported. For Odonata, data from April to the first half of May were omitted from the analyses because of their absence in traps during this period. Data for three study years (2005-2007) were combined. Displayed are the degrees of freedom and F- and P-values. Significant probabilities after correction using Holm's (1979) method are underlined.

\begin{tabular}{|c|c|c|c|}
\hline Source of variation & df & $\mathrm{F}$ & $\mathbf{P}$ \\
\hline $\begin{array}{l}\text { Gastropoda } \\
\text { Carp size } \\
\text { Time } \\
\text { Time* carp size } \\
\text { Carp biomass density }\end{array}$ & $\begin{array}{c}2,32 \\
5,160 \\
10,160 \\
1,33\end{array}$ & $\begin{array}{l}9.08 \\
5.81 \\
4.97 \\
1.92\end{array}$ & $\frac{\frac{<0.001}{<0.001}}{\frac{<0.001}{0.175}}$ \\
\hline $\begin{array}{l}\text { Hirudinea } \\
\text { Carp size } \\
\text { Time } \\
\text { Time*carp size } \\
\text { Carp biomass density }\end{array}$ & $\begin{array}{c}2,32 \\
5,160 \\
10,160 \\
1,33\end{array}$ & $\begin{array}{l}4.84 \\
4.67 \\
2.57 \\
0.31\end{array}$ & $\begin{array}{l}0.015 \\
0.003 \\
0.019 \\
0.579\end{array}$ \\
\hline $\begin{array}{l}\text { Odonata } \\
\text { Carp size } \\
\text { Time } \\
\text { Time* carp size } \\
\text { Carp biomass density }\end{array}$ & $\begin{array}{l}2,32 \\
3,96 \\
6,96 \\
1,33\end{array}$ & $\begin{array}{c}11.47 \\
4.60 \\
5.10 \\
0.36\end{array}$ & $\frac{\frac{<0.001}{0.005}}{\frac{<0.001}{0.552}}$ \\
\hline $\begin{array}{l}\text { Corixidae } \\
\text { Carp size } \\
\text { Time } \\
\text { Time*carp size } \\
\text { Carp biomass density }\end{array}$ & $\begin{array}{c}2,32 \\
5,160 \\
10,160 \\
1,33\end{array}$ & $\begin{array}{l}7.27 \\
5.50 \\
4.97 \\
1.87\end{array}$ & $\frac{\frac{0.003}{0.002}}{\frac{\leq 0.001}{0.181}}$ \\
\hline $\begin{array}{l}\text { Coleoptera } \\
\text { Carp size } \\
\text { Time } \\
\text { Time* carp size } \\
\text { Carp biomass density }\end{array}$ & $\begin{array}{c}2,32 \\
5,160 \\
10,160 \\
1,33\end{array}$ & $\begin{array}{c}35.30 \\
1.55 \\
1.25 \\
0.01\end{array}$ & $\begin{array}{c}\leq 0.001 \\
0.188 \\
0.273 \\
0.936\end{array}$ \\
\hline
\end{tabular}

df, degree of freedom. 
ponds. The comparative scarcity of macroinvertebrates, especially predatory ones (Wellborn et al., 1996; Wood et al., 2001; Dorn, 2008), in ponds stocked with larger-sized carp than in those containing small-sized carp likely results from its stronger trophic influence. Larger-sized carp are more effective in capturing macroinvertebrate (or even vertebrate) prey and have fewer handling limitations (Sibbing, 1988; Hasan and MacIntosh, 1992; Kloskowski, 2011a). Nonetheless, large-bodied predatory insects can- not be regularly taken even by large-sized carp, because they exceed fish gape limit or are capable of evading its attacks (Sibbing, 1988). They are, however, more likely to be outcompeted (Zimmer et al., 2000) by larger than small-sized fish, as the competitive effect of fish, i.e., the degree to which an individual is able to deplete resources, is intrinsically linked to individual body size (Werner and Gilliam, 1984). Large-bodied insects can be suppressed through carp depredation of eggs and larval forms that
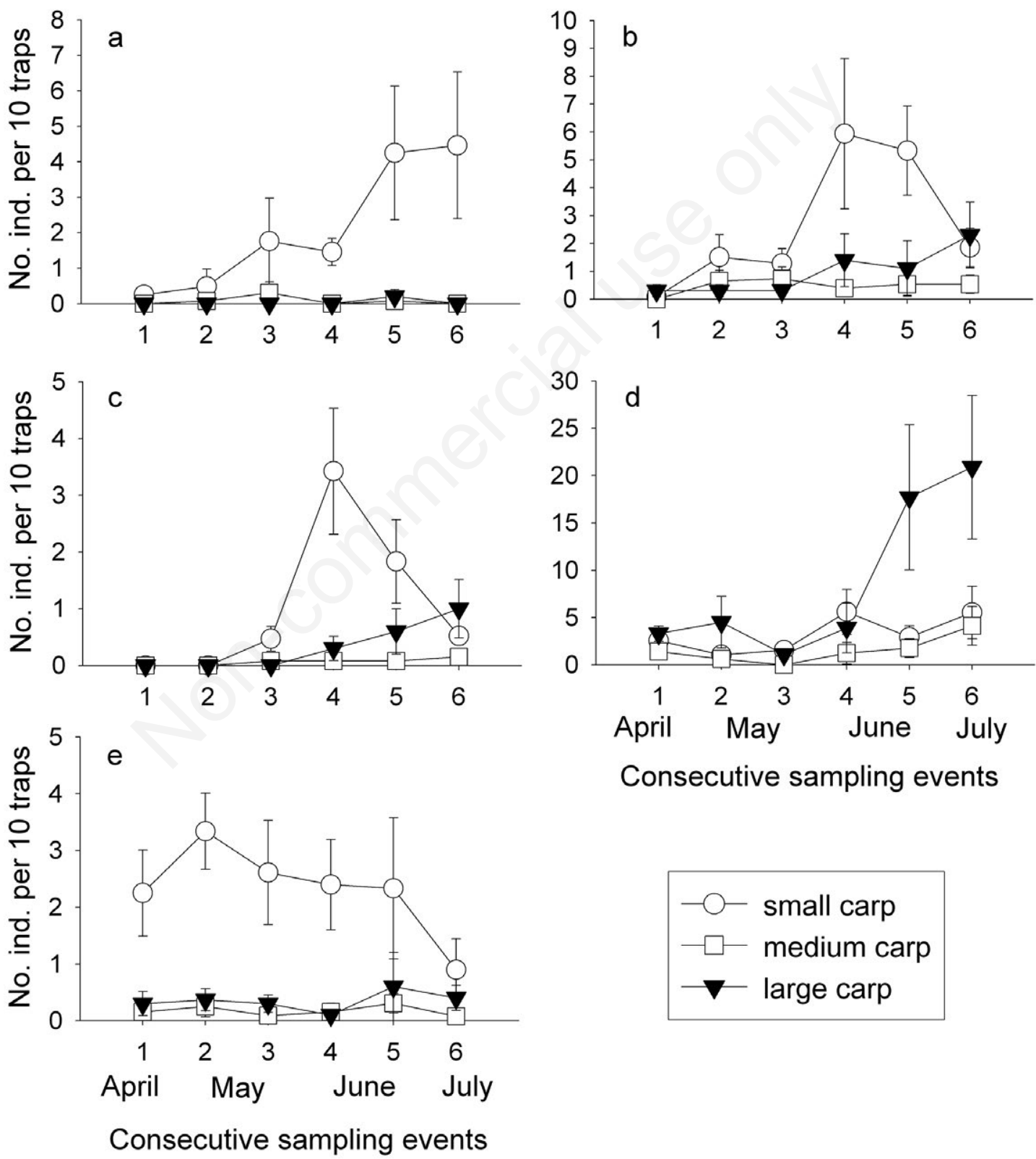

Consecutive sampling events

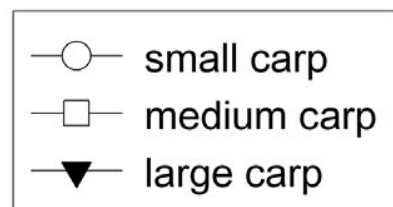

Fig. 4. Mean ( \pm standard error) relative abundances (individuals per10 traps) of macroinvertebrate taxa through time in ponds stocked with small, medium and large-sized fish: a) Gastropoda; b) Hirudinea; c) Odonata; d) Corixidae; e) Coleoptera. X-axis numbers represent consecutive sampling events (at half-month intervals). For statistical analyses see Tab. 3. 
lack effective evasive behaviour (Guziur, 1976; Crivelli, 1981). Consequently, low abundances of flying insects in ponds with larger carp can be additionally accounted for by non-consumptive effects, e.g., avoidance of potential oviposition sites occupied by an effective predator. If fish become more efficient predators/competitors with growth, greater non-consumptive effects can be expected as well (Helfman, 1989). By contrast, small-sized carp were obviously not capable of exerting as much predatory pressure on macroinvertebrates as larger fish; in fact the reverse was true, as large-bodied predatory macroinvertebrates could prey upon early stages of fish and exploit trophic resources unavailable to small carp. In our analyses, pooling taxa into broad taxonomic or functional groups is likely to mask some significant relationships, since individual Odonata or Coleoptera species have been reported to differentially respond to fish presence (Bendell and McNicol, 1995; Fairchild et al., 2000; Carchini et al., 2003; Johansson and Brodin, 2003); however, both Odonata and Coleoptera were very infrequent in ponds with larger fish. Owing to the highly contrasting densities of predaceous macroinvertebrates in the presence of small- $v s$ larger-sized fish, their potential macroinvertebrate prey, when colonising the ponds, traded off the threat of predation by larger-sized carp against that of predation by predaceous insects. For example, Lymnaeidae and Planorbidae snails, which are typically micro-herbivorous or -omnivorous grazers, were likely to find suitable abiotic habitat conditions in all pond types; environmental calcium concentrations were not a limiting factor (Dillon, 2000) because the ponds had generally high $\mathrm{pH}$ values. Although Gastropoda are preyed upon by some leeches and insects (Young and Ironmonger, 1980; Dillon, 2000), they were more abundant in ponds with small carp, where predaceous macroinvertebrates were relatively dense, which suggests that the impact of larger-sized carp on Gastropoda (Stein et al., 1975; Guziur, 1976; Richardson et al., 1990) was more powerful than the combined effect of both small fish and predaceous macroinvertebrates.

In general, our results are consistent with the prediction that the adverse effects of carp on aquatic macroinvertebrates are size-related. Therefore, the taxa which attained the highest relative abundances in the presence of large-sized fish, i.e. Ephemeroptera and Corixidae, merit particular attention. Owing to their relatively small body size, Ephemeroptera larvae can even constitute a greater proportion of the diet for small-sized carp than for larger fish (Kloskowski, 2011b). Moreover, Ephemeroptera, a common prey of predatory insects, can benefit indirectly from suppression of the latter by largerbodied fish (Batzer et al., 2000). It should be noted, however, that activity traps may be not the optimal technique to sample Ephemeroptera (Hyvönen and Nummi, 2000). Indeed, a snapshot sampling of water-column macroin- vertebrates using a dip net had previously indicated that Ephemeroptera could be more abundant in ponds stocked with small fish (Kloskowski, 2011b). Corixidae were the other group apparently less susceptible to depletion by large fish than other macroinvertebrates (Zimmer et al., 2000). Their scent gland secretions, as in some other Heteroptera, are occasionally said to deter predators (Weatherston and Percy, 1978). However, chemical defences seem only partially effective in Corixidae (Kovac and Maschwitz, 1991), as they are reported to contribute to the diet of numerous predators (reviewed by Papáček, 2001), though they rarely make up a large percentage of carp food (Guziur, 1976; Adámek et al., 2003; Kloskowski, 2011b; but see Britton et al., 2007). Owing to their fast and erratic movements (Kovac and Maschwitz, 1991) Corixidae could be a too elusive prey for carp. On the other hand, Corixidae were least abundant in the presence of medium-sized fish, which are more gape-limited when feeding on invertebrates than large carp. The distribution patterns of Corixidae contributed most to the overall dissimilarity between macroinvertebrate assemblages along the gradient of increasing fish size; the assemblages were more similar between ponds with small and large-sized fish than between ponds holding successive age (size) cohorts. The differences are probably attributable to the pronounced ontogenetic changes in the foraging behaviour of carp; medium-sized fish are more gape-limited, but can be more active in the water column than large carp (see also García-Berthou, 2001). Thus, with fish growth, predatory pressure on macroinvertebrates may generally increase, but varies from taxon to taxon.

While trophic and related behavioural effects of fish are general findings in aquatic ecosystems (Kloskowski, 2011a), fish-driven transition to a turbid state, involving changes in physico-chemical characteristics and enhancement of phytoplankton production, may be responsible for a decline in habitat conditions for many invertebrates (Parkos et al., 2003; Matsuzaki et al., 2009). Under turbid water conditions, submerged vegetation, which provides structural refugia, foraging resources and/or oviposition microhabitats (Crowder and Cooper, 1982; Nelson and Bonsdorff, 1990; Diehl and Kornijów, 1998; Bazzanti et al., 2009), disappears (Scheffer, 1989; Miller and Crowl, 2006). Parkos et al. (2003) and Miller and Crowl (2006) attributed the lowered densities of some macroinvertebrates in the presence of carp in their experiments to decreased macrophytes abundance and changes in composition due to carp feeding activities. The impact on submerged macrophytes can be size-specific as well, because larger carp are capable of stronger physical disturbance and resuspension of sediments (Driver et al., 2005; Matsuzaki et al., 2009). We did not find any significant relationship between carp size and the abundance of sub- 
merged vegetation in the study ponds, but pond colonisation by macrophytes tolerant of turbid conditions, such as Myriophyllum spicatum Linnaeus, 1753, might have contributed to this pattern (Nieoczym and Kloskowski, 2014; see also Lougheed et al., 1998; Chumchal et al., 2005; Britton et al., 2007). Nonetheless, the amount of submerged vegetation significantly explained differences among macroinvertebrate assemblages in our study system. However, other parameters indicative of transition to a turbid state, namely water transparency and dissolved oxygen, which are considered negative indicators of turbidity (Scheffer, 1989; Stewart and Downing, 2008), were either not related to macroinvertebrate abundance patterns or even negatively associated with some taxa. With regard to dissolved oxygen, air-breathing insects tolerant of anoxia were more numerous in ponds than gill-breathing organisms, such as Ephemeroptera larvae, which were potentially limited by dissolved oxygen availability (Chapman et al., 2004). For those invertebrates that depend on dissolved oxygen, oxygen conditions could be, up to a certain level of oxygen depletion, of secondary importance (Chapman et al., 2004) compared to carp trophic impact. Most macroinvertebrates were associated with extensive cover of emergent vegetation which apparently provided shelter from fish predation (Diehl and Kornijów, 1998). However, emergent macrophytes transfer oxygen to the atmosphere (Sculthorpe, 1967) and shade submerged macrophytes and algae; indeed, dissolved oxygen and emergent vegetation cover defined the opposite gradients of the first CCA axis in our study. Although ponds with larger-sized fish were subject to more intense bioturbation, as indicated by water transparency patterns, they were not more oxygen-poor than those containing smallsized fish (Driver et al., 2005). This might be attributable to the greater average surface area of ponds stocked with larger fish. As the solubility of oxygen varies inversely with water temperature (Wetzel, 1983) and water in smaller ponds warms up faster, small ponds are more prone to anoxic conditions in summer (Williams, 1987).

Except Corixidae, no taxa were associated with pond duration. However, pond period, which defined the second CCA axis, was of lesser importance for macroinvertebrate composition than fish size. The variation in hydroperiod was presumably insufficient to induce shifts in macroinvertebrate communities because all the ponds studied were artificially filled and drained every year or every other year, so water permanence was not associated with the differences in limnological characteristics typical of natural ponds (Bazzanti et al., 2009). Moreover, most species colonizing ponds are likely to be adapted to unpredictable environmental changes (Batzer et al., 2004). Although carp impacts have been reported to be densitydependent (but not necessarily linearly related; Lougheed et al., 1998; Parkos et al., 2003; Chumchal et al., 2005;
Matsuzaki et al., 2009), we failed to find compelling relationships between total carp biomass and macroinvertebrates. Since the effects of fish size and total biomass were correlated due to distinctly lower standing biomass of YOY stocks, it was difficult to separate their relative magnitudes, and the density effect was presumably to some degree overshadowed by the more powerful influence of individual size (García-Berthou, 2001; Driver et $a l ., 2005)$. However, ponds with medium- and large-sized carp supported on average similar densities of carp, while significant differences between macroinvertebrate communities were observed. As the ponds with YOY carp remained fishless until mid-May and the size of individual fry was very small at stocking, one may argue that these ponds functioned more like fishless systems (Corti et al., 1997; Paszkowski and Tonn, 2000; Dorn, 2008) during the first weeks after stocking. Nonetheless, some macroinvertebrates reached their highest abundances in these ponds in June-July, when the YOY fish attained considerable standing biomass.

Emergent vegetation cover proved to be important in explaining the patterns of macroinvertebrate diversity (Wood et al., 2001). As the extent of emergent vegetation is apparently largely independent of carp presence and size distribution, enhancement of emergent vegetation might be an appropriate management strategy for maintaining biodiversity in aquatic systems dominated by carp.

\section{CONCLUSIONS}

Our results contribute to the growing body of evidence that size dependencies can drive the outcomes of both direct and indirect interactions in aquatic food-webs (Morin, 1984; Werner and Gilliam, 1984). In our study most macroinvertebrates, especially the predatory ones, responded to a gradient of fish size. Although individual prey species exploited by fish can simultaneously be positively affected by release from predation or competition by other invertebrates (Diehl, 1992; Batzer et al., 2000), few taxa proved to be capable of persisting in presence of larger-sized carp. Our results suggest that size structure of fish populations may be of no less importance than a fish presence-absence dichotomy. Despite the bad reputation of fish with respect to biodiversity conservation management, ponds which harbour fish, but only smallsized fish may support high macroinvertebrate diversity (Corti et al., 1997; Paszkowski and Tonn, 2000; Carchini et al., 2003). Our findings also provide an argument against fish stocking in ponds or lakes which do not naturally support fish or support only small fish. For commercial reasons the species introduced are usually potentially large-bodied, and thus have the capacity to exert a more acute impact. Even if unstable environmental conditions (e.g., protracted periods of hypoxia typical for shallow waters; Penttinen and Holopainen, 1992; 
Paszkowski and Tonn, 2000) will not allow the fish to grow to a commercially attractive size, they may achieve sufficient size to disrupt local communities. On the other hand, some unwanted species, such as carp, may reproduce successfully despite environmental instability, or even benefit from it (Bajer and Sorensen, 2010). Future research should address interactions coupling distribution of body size in macroinvertebrate communities with size structure of fish populations (Diehl, 1992; Corti et al., 1997; García-Berthou, 2001) and examine them in contexts of coexistence of more than one fish species (Nowlin and Drenner, 2000).

Causal links to mechanisms of invertebrate diversity loss caused by omnivorous fish, which affect multiple ecosystem properties in a number of ways, are inevitably complex (Miller and Crowl, 2006; Stewart and Downing, 2008; Wahl et al., 2011). Prominent habitat features, such as submerged vegetation, which dampen fish trophic topdown impact (Nelson and Bonsdorff, 1990; Diehl, 1992; Diehl and Kornijów, 1998; Paukert and Willis, 2003) are likely to simultaneously be altered to varying degrees by fish through non-consumptive mechanisms (Matsuzaki et al., 2009). Changes in macroinvertebrate communities can substantially influence both top-down and bottom-up pathways in lake or pond ecosystems (Miller and Crowl, 2006; Wahl et al., 2011). Distinct size-structure of fish, a common feature of real populations, adds to this complex picture an essential dimension to understand the web of interactions and relationships organising aquatic communities containing fish.

\section{ACKNOWLEDGMENTS}

We would like to thank the fisheries managers M. Filipiak, J. Orzepowski and M. Sagan for providing access to the ponds. We are grateful to the many students and volunteers who helped with fieldwork. This study was partially supported by the Polish Ministry of Science and Higher Education (MNiSW) grant no. 2 P04 G 05030 to J.K.

\section{REFERENCES}

Adámek Z, Sukop I, Moreno Rendón P, Kouřil J, 2003. Food competition between $2+$ tench (Tinca tinca L.), common carp (Cyprinus carpio L.) and bigmouth buffalo (Ictiobus cyprinellus Val.) in pond polyculture. J. Appl. Ichthyol. 19:165-169.

Bajer PG, Sorensen PW, 2010. Recruitment and abundance of an invasive fish, the common carp, is driven by its propensity to invade and reproduce in basins that experience winter-time hypoxia in interconnected lakes. Biol. Invasions 12:1101-1112.

Batzer DP, Palik BJ, Buech R, 2004. Relationships between environmental characteristics and macroinvertebrate communities in seasonal woodland ponds of Minnesota. J. N. Am. Benthol. Soc. 23:50-68.

Batzer DP, Pusateri CR, Vetter R, 2000. Impacts of fish preda- tion on marsh invertebrates: direct and indirect effects. Wetlands 20:307-312.

Bazzanti M, Della Bella V, Grezzi F, 2009. Functional characteristics of macroinvertebrate communities in Mediterranean ponds (Central Italy): influence of water permanence and mesohabitat type. Ann. Limnol.-Int. J. Lim. 45:29-39.

Bendell BE, McNicol DK, 1995. Lake acidity, fish predation, and the distribution and abundance of some littoral insects. Hydrobiologia 302:133-145.

Bremigan MT, Garvey JE, Stein RA, Schaus MH, Vanni MJ, Wissing TE, 1997. Nitrogen and phosphorous excretion by detritivorous gizzard shad in a reservoir ecosystem. Limnol. Oceanogr. 42:1386-1397.

Britton JR, Boar RR, Grey J, Foster J, Lugonzo J, Harper DM, 2007. From introduction to fishery dominance: the initial impacts of the invasive carp Cyprinus carpio in Lake Naivasha, Kenya, 1999 to 2006. J. Fish Biol. 71:239-257.

Carchini GD, Domenico M, Pacione T, Solimini AG, Tanzilli C, 2003. Species distribution and habitat features in lentic Odonata. Ital. J. Zool. 70:39-46.

Chapman LJ, Schneider KR, Apodaca C, Chapman CA, 2004. Respiratory ecology of macroinvertebrates in a swamp-river system of East Africa. Biotropica 36:572-585.

Chumchal MM, Nowlin WH, Drenner RW, 2005. Biomass-dependent effects of common carp on water quality in shallow ponds. Hydrobiologia 545:271-277.

Clarke KR, Green RH, 1988. Statistical design and analysis for a 'biological effects' study. Mar. Ecol.-Prog. Ser. 46:213-226.

Corti D, Kohler SL, Sparks RE, 1997. Effects of hydroperiod and predation on a Mississippi River floodplain invertebrate community. Oecologia 109:154-165.

Crivelli AJ, 1981. The biology of the common carp, Cyprinus carpio L. in the Camargue, southern France. J. Fish Biol. 18:271-290.

Crowder LB, Cooper WE, 1982. Habitat structural complexity and the interaction between bluegills and their prey. Ecology 63:1802-1813.

Diehl S, 1992. Fish predation and benthic community structure: the role of omnivory and habitat complexity. Ecology 73 : 646-1661.

Diehl S, Kornijów R, 1998. Influence of submerged macrophytes on trophic interactions among fish and macroinvertebrates, $p$. 24-46. In: E. Jeppesen, M. Søndergaard, M. Søndergaard and K. Christoffersen (eds.), The structuring role of submerged macrophytes in lakes. Springer, New York.

Dillon RT, 2000. The ecology of freshwater molluscs. Cambridge University Press: 509 pp.

Dorn NJ, 2008. Colonization and reproduction of large macroinvertebrates are enhanced by drought-related fish reductions. Hydrobiologia 605:209-218.

Driver PD, Closs GP, Koen T, 2005. The effects of size and density of carp (Cyprinus carpio L.) on water quality in an experimental pond. Arch. Hydrobiol. 163:117-131.

Fairchild GW, Faulds AM, Matta JF, 2000. Beetle assemblages in ponds: effects of habitat and site age. Freshwater Biol. 44:523-534.

García-Berthou E, 2001. Size- and depth-dependent variation in habitat and diet of the common carp (Cyprinus carpio). Aquat. Sci. 63:466-476.

Gustafsson P, Bergman E, Greenberg LA, 2010. Functional re- 
sponse and size-dependent foraging on aquatic and terrestrial prey by brown trout (Salmo trutta L.). Ecol. Freshw. Fish 19:170-177.

Guziur J, 1976. The feeding of two year old carp (Cyprinus carpio L.) in a vendance Lake Klawój. Ekol. Pol.-Pol. J. Ecol. 24:211-235.

Hammer O, Harper DAT, Ryan PD, 2001. PAST: paleontological statistics software package for education and data analysis. Palaeontol. Electron. 4:1-9.

Hasan MR, MacIntosh DJ, 1992. Optimum food particle size in relation to body size of common carp, Cyprinus carpio L., fry. Aquac. Res. 23:315-325.

Helfman GS, 1989. Threat-sensitive predator avoidance in damselfish-trumpetfish interactions. Behav. Ecol. Sociobiol. 24:47-58.

Holm S, 1979. A simple sequentially rejective multiple test procedure. Scand. J. Stat. 6:65-70.

Hyvönen T, Nummi P, 2000. Activity traps and the corer: complementary methods for sampling aquatic invertebrates. Hydrobiologia 432:121-125.

Johansson F, Brodin T, 2003. Effects of fish predators and abiotic factors on dragonfly community structure. J. Freshwater Ecol. 18:415-423.

Kloskowski J, 2010. Fish farms as amphibian habitats: factors affecting amphibian species richness and community structure at carp ponds in Poland. Environ. Conserv. 37:187-194.

Kloskowski J, 2011a. Consequences of the size structure of fish populations for their effects on a generalist avian predator. Oecologia 166:517-530.

Kloskowski J, 2011b. Differential effects of age-structured common carp (Cyprinus carpio) stocks on pond invertebrate communities: implications for recreational and wildlife use of farm ponds. Aquacult. Int. 6:1151-1164.

Kloskowski J, 2011c. Impact of common carp Cyprinus carpio on aquatic communities: direct trophic effects versus habitat deterioration. Fundam. Appl. Limnol. 178:245-255.

Kovac D, Maschwitz U, 1991. The function of the metathoracic scent gland in corixid bugs (Hemiptera: Corixidae): secretiongrooming on the water surface. J. Nat. Hist. 25:331-340.

Lake PS, 2003. Ecological effects of perturbation by drought in flowing waters. Freshwater Biol. 48:1161-1172.

Lougheed VL, Crosbie B, Chow-Fraser P, 1998. Predictions on the effect of common carp (Cyprinus carpio) exclusion on water quality, zooplankton and submergent macrophytes in a Great Lakes wetland. Can. J. Fish. Aquat. Sci. 55:1189-1197.

Margalef R, 1958. Information theory in ecology. Gen. Syst. 3:36-71.

Mark W, Hofer R, Wieser W, 1987. Diet spectra and resource partitioning in the larvae and juveniles of three species and six cohorts of cyprinids from a subalpine lake. Oecologia 71:388-396.

Martínez-Sanz C, Fernández-Aláez C, García-Criado F, 2012. Richness of littoral macroinvertebrate communities in mountain ponds from NW Spain: what factors does it depend on? J. Limnol. 71:e16.

Matsuzaki SS, Usio N, Takamura N, Washitani I, 2009. Contrasting impacts of invasive engineers on freshwater ecosystems: an experiment and meta-analysis. Oecologia 158:673-686.

Michaletz PH, Doisy KE, Rabeni CF, 2005. Influences of pro- ductivity, vegetation, and fish on macroinvertebrate abundance and size in Midwestern USA impoundments. Hydrobiologia 543:147-158.

Miller SA, Crowl TA, 2006. Effects of common carp (Cyprinus carpio) on macrophytes and invertebrate communities in a shallow lake. Freshwater Biol. 51:85-94.

Morin PJ, 1984. The impact of fish exclusion on the abundance and species composition of larval odonates: results of shortterm experiments in a North Carolina farm pond. Ecology 65:53-60.

Murkin HR, Abbott PG, Kadlec JA, 1983. A comparison of activity traps and sweep nets for sampling nektonic invertebrates in wetlands. Freshw. Invertebr. Biol. 2:99-106.

Nelson WG, Bonsdorff E, 1990. Fish predation and habitat complexity: are complexity thresholds real? J. Exp. Mar. Biol. Ecol. 141:183-194.

Nieoczym M, Kloskowski J, 2014. The role of body size in the impact of common carp Cyprinus carpio on water quality, zooplankton, and macrobenthos in ponds. Int. Rev. Hydrobiol. 99:212-221.

Nowlin WH, Drenner RW, 2000. Context-dependent effects of bluegill in experimental mesocosm communities. Oecologia 122:421-426.

Palmer MW, 1993. Putting things in even better order - the advantages of canonical correspondence-analysis. Ecology $74: 2215-2230$.

Papáček M, 2001. Small aquatic and ripicolous bugs (Heteroptera: Nepomorpha) as predators and prey: The question of economic importance. Eur. J. Entomol. 98:1-12.

Parkos JJ, Santucci Jr. VJ, Wahl DH, 2003. Effects of adult common carp (Cyprinus carpio) on multiple trophic levels in shallow mesocosms. Can. J. Fish. Aquat. Sci. 60:182-192.

Paszkowski CA, Tonn WM, 2000. Community concordance between the fish and aquatic birds of lakes in northern Alberta, Canada: the relative importance of environmental and biotic factors. Freshwater Biol. 43:421-437.

Paukert CP, Willis DW, 2003. Aquatic invertebrate assemblages in shallow prairie lakes: fish and environmental influences. J. Freshwater Ecol. 18:523-536.

Penttinen OP, Holopainen IJ, 1992. Seasonal feeding activity and ontogenetic dietary shifts in crucian carp, Carassius carassius. Environ. Biol. Fish. 33:215-221.

Richardson WB, Wickham SA, Threlkeld ST, 1990. Foodweb response to the experimental manipulation of a benthivore (Cyprinus carpio), zooplanktivore (Menidia beryllina) and benthic insects. Arch. Hydrobiol. 119:143-165.

Scheffer M, 1989. Alternative stable states in eutrophic, shallow freshwater systems: a minimal model. Hydrobiol. Bull. 23:73-83.

Sculthorpe CD, 1967. The biology of aquatic vascular plants. Edward Arnold Publ.: 610 pp.

Sibbing FA, 1988. Specializations and limitations in the utilization of food resources by the carp, Cyprinus carpio: a study of oral food processing. Environ. Biol. Fish. 22:161-178.

Stein RA, Kitchell JF, Kneževic B, 1975. Selective predation by carp (Cyprinus carpio L.) on benthic molluscs in Skadar Lake, Yugoslavia. J. Fish Biol. 7:391-399.

Stewart TW, Downing JA, 2008. Macroinvertebrate communities and environmental conditions in recently constructed wetlands. Wetlands 28:141-150. 
Svensson JM, Bergman E, Andersson G, 1999. Impact of cyprinid reduction on the benthic macroinvertebrate community and implications for increased nitrogen retention. Hydrobiologia 404:99-112.

Tapia M, Zambrano L, 2003. From aquaculture goals to real social and ecological impacts: carp introduction in rural central Mexico. Ambio 32:252-257.

ter Braak CJF, 1986. Canonical correspondence analysis: a new eigenvector technique for multivariate direct gradient analysis. Ecology 67:1167-1179.

ter Braak CJF, Šmilauer P, 2002. CANOCO Reference Manual and CanoDraw for Windows User's Guide: Software for Canonical Community Ordination, ver. 4.5. Microcomputer Power: $500 \mathrm{pp}$.

Wahl DH, Wolfe MD, Santucci Jr. VJ, Freedman JA, 2011. Invasive carp and prey community composition disrupt trophic cascades in eutrophic ponds. Hydrobiologia 678:49-63.

Weatherston J, Percy JE, 1978. Venoms of Rhyncota (Hemiptera), p. 489-509. In: S. Bettini (ed.), Arthropod venoms. Springer-Verlag.
Wellborn GA, Skelly DK, Werner EE, 1996. Mechanisms creating community structure across a freshwater habitat gradient. Annu. Rev. Ecol. Syst. 27:337-363.

Werner EE, Gilliam JF, 1984. The ontogenetic niche and species interactions in size-structured populations. Annu. Rev. Ecol. Syst. 15:393-425.

Wetzel RG, 1983. Limnology. Saunders: 860 pp.

Williams DD, 1987. The ecology of temporary waters. Timber Press: 205 pp.

Wood PJ, Greenwood MT, Barker SA, 2001. The effects of amenity management for angling on the conservation value of aquatic invertebrate communities in old industrial ponds. Biol. Conserv. 102:17-29.

Young JO, Ironmonger JW, 1980. A laboratory study of the food of three species of leeches occurring in British lakes. Hydrobiologia 68:209-215.

Zimmer KD, Hanson MA, Butler MG, 2000. Factors influencing invertebrate communities in prairie wetlands: a multivariate approach. Can. J. Fish. Aquat. Sci. 57:76-85. 